\title{
Molecular and morphological exploration of a mixed population of two potato-parasiting nematode species, Globodera rostochiensis and G. pallida
}

\author{
O. DOUDA ${ }^{1 *}$, M. ZOUHAR ${ }^{2}$, M. RENČO ${ }^{3}$, M. MAREK $^{2}$
}

\begin{abstract}
${ }^{1 *}$ Crop Research Institute Prague, Division of Plant Health, Drnovská 507, 16106 Prague 6, Czech Republic, E-mail: douda@vurv.cz; ${ }^{2}$ Czech University of Life Sciences (CULS) Prague, Faculty of Agrobiology, Food and Natural Resources, Department of Plant Protection, Czech Republic; ${ }^{3}$ Institute of Parasitology of the Slovak Academy of Sciences, Department of Environmental and Plant Parasitology, Puškinova 6, 04001 Košice, Slovak Republic
\end{abstract}

\begin{abstract}
Summary
In this work, we report results of molecular and morphological analyses of a potato field population of Globodera (Nematoda: Heteroderidae) species, in Slovakia. Unexpectedly, our data show a mixed occurrence of two potato cyst nematode species, Globodera rostochiensis and $G$. pallida, in this locality. To our knowledge, this is the first report of mixed occurrence of these economically important plant-parasitic species in the same locality in the Central Europe. In addition, this finding reinforces the possibility of the cross-hybridization between these two nematode species that might result in a generation of new genotypes.
\end{abstract}

Keywords: Potato cyst nematode; Globodera rostochiensis; Globodera pallida; molecular diagnostics; morphology; population genetics; Slovakia

\section{Introduction}

The quarantine plant-parasitic nematodes are important biotic factors influencing commercial production of the agricultural commodities. Considering potatoes production, two quarantine cyst-forming nematode species are significant currently - Globodera rostochiensis and Globodera pallida. From these two species, G. rostochiensis is widespread in both Czech Republic and Slovakia, whereas G. pallida distribution is rather limited in both countries. It was firstly described from the Czech Republic in 2003 by Zouhar et al. and in 2009 in Slovakia by Hubinská et al. in 2009. The other population was recently described from the western region of Bohemia (Douda et al., 2012). It is crucial to precisely distinguish these species by phytosanitary diagnostic tools as the lack of resistant potato cultivars still exists for $G$. pallida, while occurrence of G. rostochiensis does not affect potato cultures significantly because nearly all contemporary potato cultivars are resistant or tolerant to this species.

\section{Material and methods}

Cysts of potato cyst nematode from a single locality in Central Slovakia were obtained from staff of the Central and Testing Institute in Agriculture of the Slovak Republic. Cysts were subjected to molecular and morphological analysis. DNA was isolated from embryon suspensions originating from cysts used for the previous morphological characterization. DNA was isolated using innuPREP Plant DNA Kit and isolation robot InnuPure ${ }^{\circledR}$ C16 (Analytik Jena) according to manual. DNA samples were used for amplification using multiplex PCR (Zouhar et al., 2000). This method allows distinguishing G. rostochiensis and $G$. pallida in one tube utilizing universal primer UNI 5'GCAGTTGGCTAGGGATCTTC-3', G. pallida specific primer GPA1 5'-GGTGACTCGACGATTGCTGT-3' and G. rostochiensis specific primer GRO5A 5'-ATGTTGTAC GTGCCGTACCTT-3'. These primers amplify nuclearencoded ribosomal DNA (rDNA), an DNA region that was shown to be highly valuable for classifying, molecular diagnostics and phylogeny reconstructions of diverse organisms at various taxonomic levels, including plantparasitic nematodes (Marek et al., 2010; Douda et al., 2013). PCR protocol was as follows: initial denaturation $95^{\circ} \mathrm{C}$ for $5 \mathrm{~min}$ followed by 34 cycles of PCR $(60 \mathrm{~s}$ denaturation at $94{ }^{\circ} \mathrm{C}, 45 \mathrm{~s}$ annealing at $62^{\circ} \mathrm{C}$, and $60 \mathrm{~s}$ extension at $72^{\circ} \mathrm{C}$ ) and a $4 \mathrm{~min}$ final extension at $72^{\circ} \mathrm{C}$. As positive controls for PCR amplifications, genomic DNA extracted from G. rostochiensis (population Šluknov, pathotype Ro1, Czech Republic) and DNA from G. pallida (population Chavornay, pathotype Pa3, France) were used, while genomic DNA isolated from Heterodera schachtii served as negative control. PCR products were separated on a $1 \%$ horizontal agarose electrophoresis and stained with ethidium bromide. The predicted length of the PCR products was $391 \mathrm{bp}$ for G. pallida and $239 \mathrm{bp}$ for G. rostochiensis (Fig. 1) 


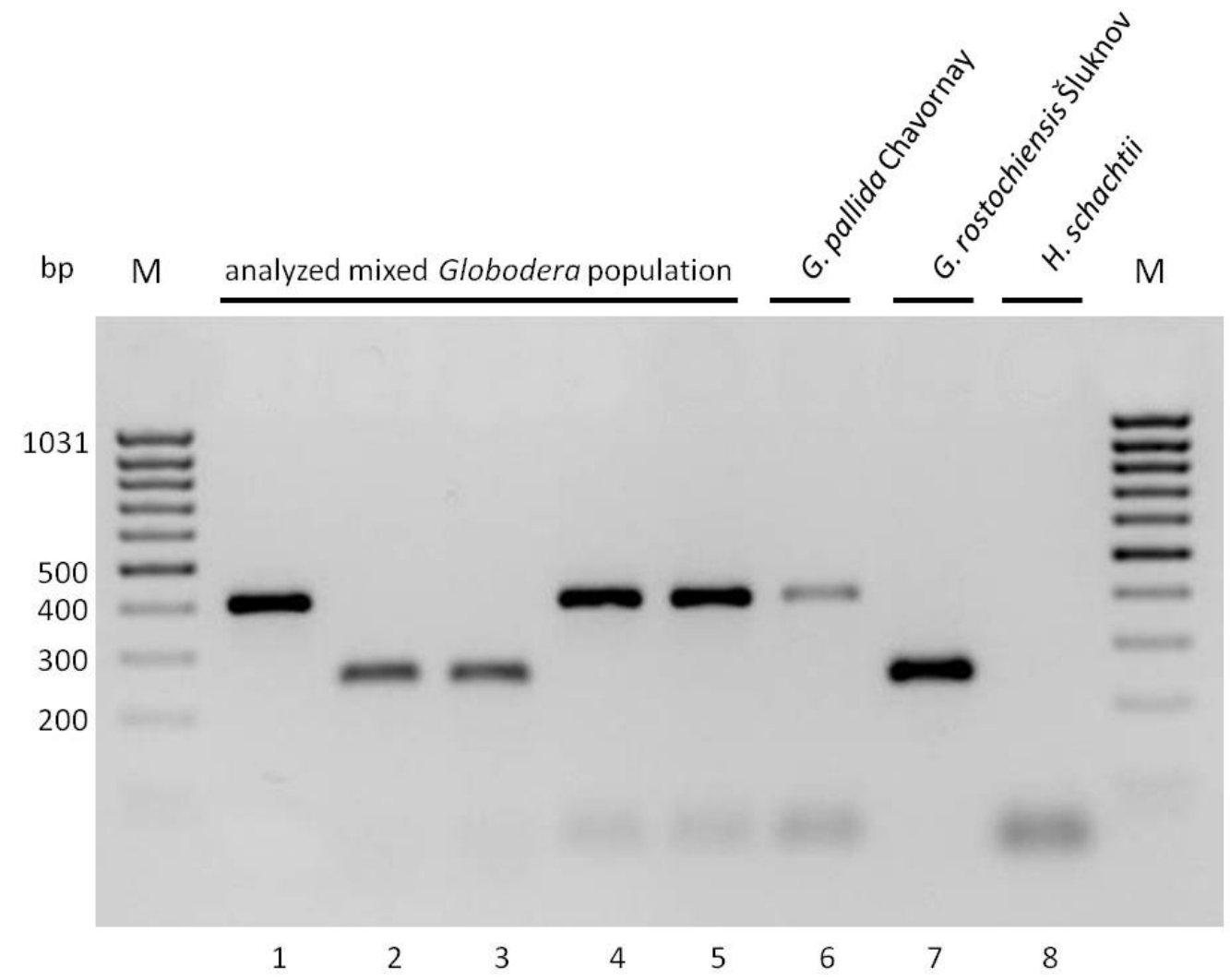

Fig. 1. Multiplex PCR-based amplification of ITS-rDNA region. Lines: 1 to 5 -genomic DNA isolated from individual cysts of the analyzed mixed Globodera population (Slovakia); 6 - genomic DNA from G. pallida (population Chavornay, pathotype Pa3, France) served as positive control, 7 genomic DNA from G. rostochiensis (population Šluknov, pathotype Ro1, Czech Republic) served as positive control, 8. - genomic DNA from Heterodera schachtii served as negative control; M - DNA ladder (MassRuler Low range, Thermo Scientific)

Morphological diagnostics was performed utilizing cysts dissection and measuring using the light microscope. $2^{\text {nd }}$ stage juveniles were obtained from cysts macerated overnight in hatching solution and measured as well. Following cyst morphological data were acquired: fenestra diameter, distance fenestra to anus, Granek's ratio (the vulva - anus distance divided by vulval basin diameter) and number of cuticular ridges between fenestra and anus. In the case of second stage juvenile following values were gained: whole body length (L), stylet length, tail length, and length of hyaline terminal part of tail. Nematological indexes a (body tength/largest body width), b (body length/pharynx length from head to pharyngeo-intestinal junction), b' (body length/pharynx length from anterior end to posterior end of glandular lobe), $\mathrm{c}$ (ration of body length to tail length) and $\mathrm{c}^{\prime}$ (ratio of tail length to body width at anus level) were calculated. All acquired data are summarized in Tables 1 and 2 .

\section{Results and discussion}

Following morphological characteristics were described: G. pallida - juveniles slightly arcuate when relaxed. Lateral field with four lines, occasionally crossed by transverse

Table 1. Morphometrics of diagnostic characters of $2^{\text {nd }}$ stage juveniles of G. pallida and G. rostochensis from Slovakia

\begin{tabular}{lcc|cc}
\hline Character & \multicolumn{2}{c|}{ G. pallida } & \multicolumn{2}{c}{ G. rostochiensis } \\
\hline & \multicolumn{2}{c|}{$\mathrm{n}=13$} & \multicolumn{2}{c}{$\mathrm{n}=32$} \\
\cline { 2 - 5 } & Range & Mean & Range & Mean \\
\hline Body length $(\mu \mathrm{m})$ & $420-540$ & 489.0 & $400-630$ & 486.0 \\
Stylet length $(\mu \mathrm{m})$ & $21.3-23.2$ & 22.9 & $18.8-23.5$ & 21.6 \\
Tail length $(\mu \mathrm{m})$ & $47.0-63.0$ & 53.8 & $42.0-58.0$ & 50.3 \\
Hyaline terminal tail length $(\mu \mathrm{m})$ & $24.0-32.0$ & 28.9 & $19.0-26.0$ & 25.1 \\
Pharynx length $(\mu \mathrm{m})$ & $94.0-105.0$ & 102.6 & $79.0-99.0$ & 94.5 \\
Head end to pharyngeal lobe end $(\mu \mathrm{m})$ & $139.0-173.0$ & 166.6 & $121.0-159.0$ & 149.3 \\
a & $24.0-27.0$ & 25.0 & $18.0-22.0$ & 20.5 \\
b & $4.0-4.6$ & 4.2 & $4.0-4.5$ & 4.3 \\
$\mathrm{~b}^{\prime}$ & $2.6-3.0$ & 2.8 & $2.2-3.1$ & 2.7 \\
$\mathrm{c}^{\prime}$ & $7.9-9.3$ & 8.7 & $7.1-9.1$ & 8.8 \\
$\mathrm{c}^{\prime}$ & $3.8-5.2$ & 4.5 & $2.9-4.5$ & 4.3 \\
\hline
\end{tabular}


Table 2. Morphometrics of diagnostic characters of cysts of G. pallida and G. rostochensis from Slovakia

\begin{tabular}{lcc|cc}
\hline Character & \multicolumn{2}{c|}{ G. pallida } & \multicolumn{2}{c}{ G. rostochiensis } \\
\cline { 2 - 5 } & \multicolumn{2}{c|}{$\mathrm{N}=8$} & \multicolumn{2}{c}{$\mathrm{N}=12$} \\
\cline { 2 - 5 } & Range & Mean & Range & Mean \\
\hline Cyst length $(\mathrm{mm})$ & $0.53-0.60$ & 0.57 & $0.38-0.75$ & 0.57 \\
Cyst width $(\mathrm{mm})$ & $0.46-0.56$ & 0.53 & $0.35-0.62$ & 0.53 \\
Fenestra diameter $(\mu \mathrm{m})$ & $21.8-25.6$ & 24.3 & $11.5-22.9$ & 17.6 \\
Distance fenestra to annus $(\mu \mathrm{m})$ & $35-58$ & 49.8 & $48-95$ & 73.2 \\
Distance fenestra to annus/fenestra diameter & $1.8-2.5$ & - & $2.5-5.9$ & - \\
Granek's ratio & $1.15-3.49$ & 2.32 & $2.1-6.5$ & 4.8 \\
Number of cuticular ridges between vulva and annus & $9-18$ & 14 & $15-23$ & 18 \\
\hline
\end{tabular}

striae. Head offset, bearing $4-6$ annuli, about $10-12 \mu \mathrm{m}$ wide at base. Stylet knobs with distinct forward projections, about $4-5 \mu \mathrm{m}$ across. Dorsal gland orifice $3.2-$ $4.8 \mu \mathrm{m}$ posterior to knobs. Metacorporeal valve $64-$ $75 \mu \mathrm{m}$, excretory pore $92-112 \mu \mathrm{m}$. Hyaline terminal part of tail $48-53 \%$ of total tail length. Terminus rounded.
Eggs 112.8 - $115.5 \mu \mathrm{m}$ long, 41.0 - $42.5 \mu \mathrm{m}$ wide, length/width 2.3 - 2.7. G. rostochiensis - Juveniles slight to slightly arcuate when relaxed. Lateral field with four lines. Head slightly offset, bearing $4-5$ annuli, about $9-$ $11 \mu \mathrm{m}$ wide at base and $4.2-4.8 \mu \mathrm{m}$ high. Stylet knobs anteriorly flattened to rounded, without forward projec-

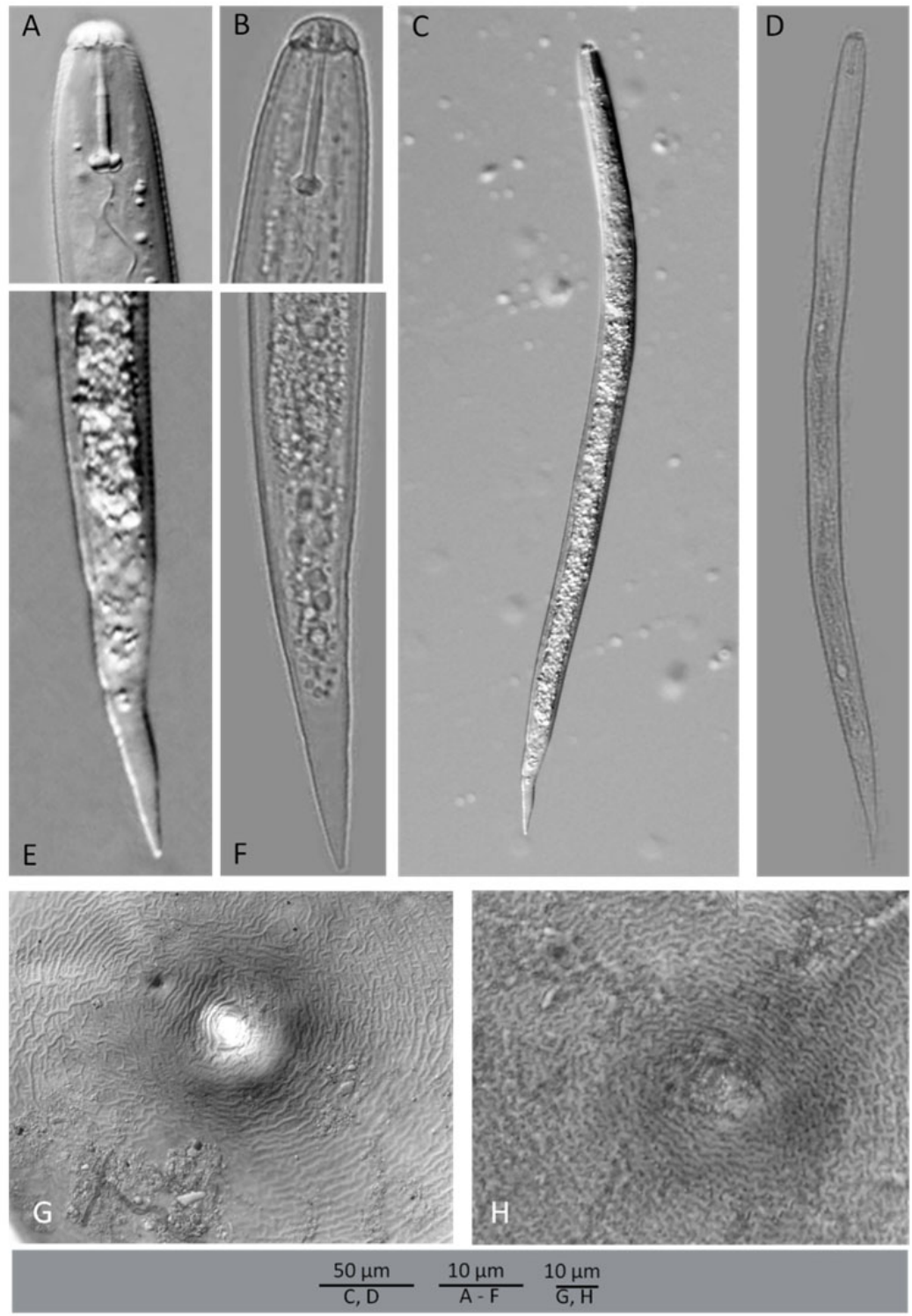

Fig. 1. Representative photographs of individual nematodes of the analyzed Globodera population: A) head, E) tail, C) $2^{\text {nd }}$ juvenile, G) cyst fenestra of G. pallida; B) head, F) tail, D) $2^{\text {nd }}$ juvenile, H) cyst fenestra of G. rostochiensis 
tions, about $3.5-3.9 \mu \mathrm{m}$ across. Dorsal gland orifice $4.3-$ $6.5 \mu \mathrm{m}$ posterior to knobs. Metacorporeal valve $63-$ $73 \mu \mathrm{m}$, excretory pore $85-97 \mu \mathrm{m}$. Hyaline terminal part of tail $48-53 \%$ of total tail length. Terminus rounded. Eggs 98.2 - $105.3 \mu \mathrm{m}$ long, $45.0-49.6 \mu \mathrm{m}$ wide, length/width $2.0-2.3$.

From the molecular and morphological data acquired in this study, it is obvious that although cysts were extracted from soil samples originating from the same single locality, two potato cyst nematode species ( $G$. rostochiensis and G. pallida) were present. It is the second reported occurrence of the mixed Potato cyst nematode in the Central Europe (Karnkowski et al., 2010). Although cross-hybridization between these two Globodera species is feasible (Brzeski, 1998), it seems to be rather unlikely event in field conditions. However, this possibility should be taken into account during diagnostics of these quarantine species, especially when considering numbers of cysts used for morphological description. In addition, molecular diagnostics-based tools were recently developed as single cyst DNA isolation or utilizing of multiplex PCR (Mullholland et al., 1996, Zouhar et al., 2000) should be used.

\section{Acknowledgement}

These results were obtained with support from a research grant 7AMB12SK141, provided by the Ministry of Education, Youth and Sport of the Czech Republic and a research project MZE0002700604 provided by the Ministry of Agriculture of the Czech Republic Republic and research project of Slovak Research and Development Agency APVV no. SK-CZ-0086-11.

\section{References}

BRZESKI, M. W. (1998): Nematodes of Tylenchina in Poland and temperature Europe. Muzeum i Instytut Zoologii, Polska Akademia Nauk, Warszawa, 397 pp.

DOUDA, O., ZOUHAR, M., URBAN, J., ČERMÁK, V., GAAR, V.
(2012): Identification and Characterization of Pale Po-tato Cyst Nematode (Globodera pallida) in Teplá, the Czech Republic. Plant Dis. - Dis. Notes, 96: 1386. DOI: 10.1094/PDIS-03-12-0305-PDN

DoudA, O., MAReK, M., Zouhar, M., RYŠÁneK, P. (2013): Insights into the structure and phylogeny of the 28S rRNA expansion segments D2 and D3 of the plantinfecting nematodes from the genus Ditylenchus (Nematoda: Anguininae). Phytopathol. Mediterr., 52: $84-97$

HubinskÁ, A., BAROK, S., KuBÍK, J. (2009): Monitoring of the Potato Cyst Nematode in Slovakia in 2008 (In Slovak). In: Report of the Central and Testing Institute in Agriculture of the Slovak Republic, 5 pp.

KARnKOWSKI, W., KACZMARE, A., DOBOSZ, R., WieczoreK, P., OBRĘPALSKA-STĘPLOWSKA, A. (2010): Occurrence of the white potato nematode Globodera pallida (Stone, 1973) Behrens, 1975 (Nematoda: Heteroderidae) on the territory of Poland. Prog. Plant Prot./Post. Ochr. Roślin, 52 (4): 1087 - 1092 (In Polish)

MAREK, M., Zouhar, M., DoudA, O., MazÁKovÁ, J., RYŠÁNEK, P., (2010): Bioinformatics-assisted characterization of the ITS1-5.8S-ITS2 segments of nuclear rRNA gene clusters, and its exploitation in molecular diagnostics of European crop-parasitic nematodes of the genus Ditylenchus. Plant Pathol., 59: 931 - 943

Mulholland, V., Carde, L., O’Donnell, K. J., Fleming, C. C., Powers, T. O. (1996): Use of the polymerase chain reaction to discriminate potato cyst nematode at the species level. In: FARNHAM, G. M. (Ed) BCPC Proceedings No. 65, Diagnostics in crop production. The British Crop Protection Council, pp. $247-252$

ZOUHAR, M., RYŠÁNEK, P., KoČOVÁ, M. (2000): Detection and differentiation of the potato cyst nematodes Globodera rostochiensis and Globodera pallida by PCR. Plant Prot. Sci., 36: $81-84$

ZOUHAR, M., RYŠÁNEK, P., GAAR, V. (2003): First Report of the Potato Cyst Nematode (Globodera pallida) in the Czech Republic. Plant Dis. - Dis. Notes, 87: 98. DOI: 10.1094/PDIS.2003.87.1.98A 